\title{
Compensating Artificial Airway Resistance via Active Expiration Assistance
}

\author{
Steffen Wirth MD, Luc Seywert MD, Johannes Spaeth MD, and Stefan Schumann PhD
}

\begin{abstract}
BACKGROUND: Artificial airway resistance as provided by small-lumen tracheal tubes or catheters increases the risk of intrinsic PEEP (PEEPi). We hypothesized that by active expiration assistance, larger minute volumes could be generated without causing PEEPi compared with conventional mechanical ventilation when using small-lumen tracheal tubes or a cricothyrotomy catheter. METHODS: We investigated the active expiration assistance in a physical model of the respiratory system and estimated its hypothetical performance in terms of maximal flow generated with endotracheal tubes ranging from 3.0 to $8.0 \mathrm{~mm}$ inner diameter (ID); with microlaryngeal tubes of 4.0, 5.0, and $6.0 \mathrm{~mm} \mathrm{ID}$; and with a cricothyrotomy catheter. Furthermore, we determined the minute volumes that could be achieved without generating PEEPi by ventilating a physical lung model using conventional mechanical ventilation or using active expiration assistance. RESULTS: The inspiratory and expiratory flow during active expiration assistance increased with increasing supply flow and decreased with decreasing ID of the connected endotracheal tubes (both $P<.001$ ). With small-lumen tracheal tubes, the active expiration assistance generated similar or higher minute volumes than conventional ventilation. Conventional mechanical ventilation with PEEPi $<1 \mathrm{~cm} \mathrm{H} \mathrm{H}_{2} \mathrm{O}$ was not achievable via a microlaryngeal tube of $4.0 \mathrm{~mm}$ ID and smaller lumen tubes. CONCLUSIONS: For mechanical ventilation via small-lumen tubes or thin catheters, active compensation of airway resistance might be a necessary means to generate adequate minute ventilation without causing PEEPi. Active expiration assistance can generate reasonable respiratory minute volumes via small-lumen tubes or thin catheters. Key words: mechanical ventilation; airway resistance; intrinsic peep; difficult airway; respiratory system mechanics; active expiration. [Respir Care 2016;61(12):1597-1604. (ㅇ 2016 Daedalus Enterprises]
\end{abstract}

\section{Introduction}

Setting options for controlled mechanical ventilation primarily allow adjustment to the parameters of the inspiratory phase (eg, the inspiratory flow or the length of the

\footnotetext{
The authors are affiliated with the Department of Anesthesiology and Intensive Care Medicine, University Medical Center Freiburg, Freiburg, Germany.

This work was supported by institutional funding. The authors have disclosed no conflicts of interest.

Correspondence: Steffen Wirth MD, Department of Anesthesiology and Intensive Care Medicine, University Medical Center Freiburg, Hugstetter Strasse 55, D-79106 Freiburg, Germany. E-mail: steffen.wirth@uniklinik-freiburg.de.
}

DOI: $10.4187 /$ respcare. 04817 plateau phase). By contrast, with the exception of PEEP and expiration time, few options are available to influence the expiratory phase, although it constitutes more than half of the breathing cycle under normal conditions, both during spontaneous breathing and under typical mechanical ventilation. As a result, the courses of pressure and flow during expiration are determined by the compliance of the patient's respiratory system and the sum of the expiratory resistance of both the native and artificial airways.

The endotracheal tube (ETT) is the major component between the ventilator and the biological respiratory gas exchange system. Due to its small inner diameter (ID) and flow-dependent fluid mechanics, the endotracheal tube is the most prominent resistive element in the respiratory system. ${ }^{1}$ Specific endotracheal tubes with particularly small cross sections (ie, microlaryngeal tubes) are used during surgical procedures on the vocal cords to give the surgeon an optimal field of view. The respiratory system resistance 
is considerably greater when microlaryngeal tubes are used compared with normal ETTs. As a consequence, the risk of incomplete expiration and the resulting intrinsic PEEP (PEEPi) is increased accordingly. ${ }^{2-5}$ An emergency ventilation system (Ventrain, Dolphys Medical, Eindhoven, The Netherlands) that ensures a sufficient respiratory minute volume via needle cricothyrotomy has been developed. ${ }^{6}$ This system is based on the manual control of an approximately constant flow during inspiration and expiration.

We hypothesized that using such an active system with ETTs of low ID and with microlaryngeal tubes, larger minute volumes could be generated without resulting increases in PEEPi when compared with conventional mechanical ventilation with passive expiration. Therefore, we investigated the tracheal tube-dependent minute volume that can be generated using the emergency ventilation system as an active expiration assistance system and compared it with the minute volume generated using conventional mechanical ventilation without causing noticeable PEEPi.

\section{Methods}

To investigate the feasibility of active expiration assistance in an intra-operative setting, we estimated its hypothetical performance by measurement of maximal flow in various tracheal tubes. Additionally, we estimated the minute volumes that could be achieved by ventilating a physical lung model (Model 2600i Dual Adult, Michigan Instruments, Grand Rapids, Michigan) via a mechanical ventilator or manually using active expiration assistance.

All settings were tested with ETTs ranging from 3.0 to $8.0 \mathrm{~mm}$ ID, with microlaryngeal tubes of 4.0, 5.0, and 6.0 ID and with a cricothyrotomy catheter (Cricath, Dolphys Medical, Eindhoven, The Netherlands) that is provided with the Ventrain System (Table 1). To rule out manufacturer-specific differences, only one brand of tubes (Mallinckrodt, Covidien, Athlene, Ireland) were investigated in this study.

Pressure and flow were recorded with a sample rate of $200 \mathrm{~Hz}$ using software that was self-developed in a graphic programming language (LabView 7.1, National Instruments Corp., Austin, Texas). The measured data were subsequently analyzed with MATLAB (R2011a, MathWorks, Natick, Massachusetts) functions developed for this purpose.

\section{Generable Flow With Active Expiration Assistance}

We realized the active expiration assistance by utilizing the Ventrain emergency ventilation system. We aimed to apply this device not only in its designated usage (with the dedicated cricothyrotomy catheter) but also to use the active generation of expiratory flow for achieving an en-

\section{QUICK LOOK}

\section{Current knowledge}

The expiration phase proceeds passively during conventional mechanical ventilation. Thereby, expiration time is particularly prolonged when small tracheal tubes are used. Sufficient minute volumes may not be achievable, or intrinsic PEEP may develop.

\section{What this paper contributes to our knowledge}

In a lung model, an expiratory assistance device provided negative airway pressure without generating negative pressure in the simulated lung. Compared to passive exhalation, this system provided better maintenance of minute ventilation without intrinsic PEEP with a small endotracheal tube of cricothyrotomy catheter.

hanced expiration that might improve the mechanical ventilation in terms of reduced risk for PEEPi compared with the passive expiration during conventional mechanical ventilation.

Reasoned by the technical concept of the active expiration assistance device, the supply flow is directed to the lungs during inspiration (Fig. 1). During expiration, a negative pressure is generated inside the device based on the Bernoulli principle. The negative pressure generates an expiratory flow that depends on the applied supply flow and the resistance of the connecting system, which is mainly determined by the tracheal tube being used. To determine the maximal flow within tracheal tubes or the cricothyrotomy catheter, the tube or catheter was connected to the active expiration assistance device and positioned within a tracheal model at its distal end. To investigate the potential performance of the active expiration assistance in terms of variable flows, we varied the supply flow around the recommended value of $250 \mathrm{~mL} / \mathrm{s}$. The device was connected to a gas supply source with a pressure-compensated flow regulator (supply pressure 5 bars), and inspiratory and expiratory flow were measured at supply flow of 200 and $300 \mathrm{~mL} / \mathrm{s}$ using a pneumotachograph (Fleisch type 2, Dr Fenyves \& Gut, Hechingen, Germany). Every measurement of generable flow was repeated 3 times, after which the complete system was rebuilt before carrying out the next set of measurements.

\section{Minute Ventilation With Volume Controlled Ventilation}

In order to investigate in which situations the use of active expiration assistance would be preferable compared with conventional ventilation with passive expiration, we 
Table 1. Characteristics of Tested Endotracheal Tubes and Catheters

\begin{tabular}{|c|c|c|c|c|c|}
\hline Manufacturer & Product & $\begin{array}{c}\text { Inner } \\
\text { Diameter (mm) }\end{array}$ & $\begin{array}{c}\text { Outer } \\
\text { Diameter }(\mathrm{mm})\end{array}$ & $\begin{array}{l}\text { Length Without } \\
\text { Connector (mm) }\end{array}$ & $\begin{array}{l}\text { Length With } \\
\text { Connector }(\mathrm{mm})\end{array}$ \\
\hline Covidien & Hi-Contour & 8.0 & 10.9 & 329 & 360 \\
\hline Covidien & Hi-Contour & 7.0 & 9.6 & 303 & 339 \\
\hline Covidien & Hi-Contour & 6.0 & 8.2 & 284 & 317 \\
\hline Covidien & Hi-Contour & 5.0 & 6.9 & 246 & 274 \\
\hline Covidien & Hi-Contour & 4.0 & 5.6 & 206 & 232 \\
\hline Covidien & Hi-Contour & 3.0 & 4.3 & 167 & 190 \\
\hline Covidien & MLT & 6.0 & 8.2 & 323 & 368 \\
\hline Covidien & MLT & 5.0 & 6.9 & 323 & 368 \\
\hline Covidien & MLT & 4.0 & 5.6 & 323 & 368 \\
\hline Dolphys & Cricath & 2.0 & 3.0 & 75 & 95 \\
\hline
\end{tabular}

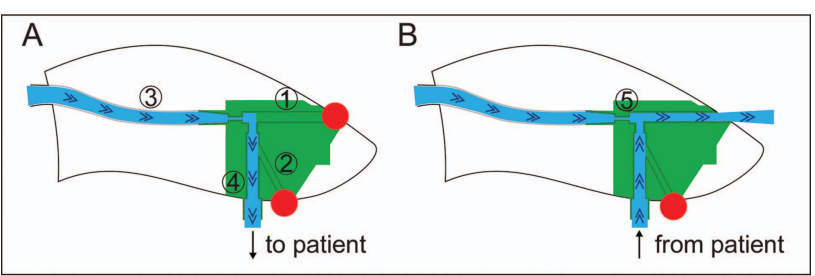

Fig. 1. Cross-sectional cut through the active expiration assistance device. During inspiration (A), the outflow tract (1) and the side port (2) are closed (red circles), and the supply flow (3) is directed to the patient via the patient tract (4). During expiration (B), the side port is closed, and the supply flow is directed to the jet nozzle (5). There, following the Bernoulli principle, it creates a negative pressure, resulting in an active expiratory flow. When the side port is open, the system is inactivated (not shown).

aimed at simulating realistic situations in which the tracheal tube used might contribute relevantly to PEEPi. Therefore, the lung model was set to a compliance of $80 \mathrm{~mL} / \mathrm{cm} \mathrm{H}_{2} \mathrm{O}$ and a resistance of $10 \mathrm{~mL} / \mathrm{cm} \mathrm{H}_{2} \mathrm{O}$. The respective endotracheal or microlaryngeal tubes or cricothyrotomy catheter was placed in a tracheal model including a pressure measurement site, and the end of the tracheal model was attached to the physical lung model via a pneumotachograph. The physical lung model was ventilated in the volume controlled mode using an intensive care ventilator (Evita 4, Dräger Medical, Lübeck, Germany). Ventilation was set to achieve realistic situations with an increased risk for PEEPi. A PEEP of $5 \mathrm{~cm} \mathrm{H}_{2} \mathrm{O}$ and a constant tidal volume of $640 \mathrm{~mL}$ were selected as ventilation parameters. With these fixed parameters, inspiratory-expiratory ratios of $1: 1.5$ and $1: 1$ and frequencies of $6,9,12$, and 15 breaths/min were combined.

Airway pressure, tracheal pressure, pressure inside the lung model, and flow were recorded, and PEEPi was determined as the difference between pressure inside the lung model at the end of expiration and set PEEP $(5 \mathrm{~cm}$ $\mathrm{H}_{2} \mathrm{O}$ ). PEEPi was classified as noticeable when it exceeded $1 \mathrm{~cm} \mathrm{H}_{2} \mathrm{O}$. The resulting minute volumes were calculated by multiplying tidal volume with frequency. Each mea- surement on minute ventilation included $\geq 15$ consecutive breathing cycles and was repeated 3 times, after which the complete system was rebuilt before carrying out the next set of measurements.

\section{Minute Ventilation With Active Expiration Assistance}

To determine minute volumes achievable with active expiration assistance, the lung model was manually ventilated with the device, guided by eyeballing of the lungpressure display with which the model is equipped. Minute ventilation was calculated by multiplying tidal volume with frequency. Manually operating the active expiration assistance device might have incorporated personal variabilities (eg ventilation rhythm variation or incomplete manual sealing of the device's orifices). Therefore, we additionally calculated the achievable minute volumes from the flow that was generable with the respective endotracheal or microlaryngeal tubes and the cricothyrotomy catheter connected to the identical physical model, as described above (Fig. 2).

The maximally achievable minute volume $\left(\dot{\mathrm{V}}_{\mathrm{E} \max }\right)$ of each setting was then calculated with the equation, $\dot{\mathrm{V}}_{\mathrm{E} \max }$ $=60 \times \dot{\mathrm{V}}_{\text {insp }} \times\left|\dot{\mathrm{V}}_{\text {exp }}\right| /\left(\dot{\mathrm{V}}_{\text {insp }}+\left|\dot{\mathrm{V}}_{\text {exp }}\right|\right)$, where $\dot{\mathrm{V}}_{\text {insp }}$ is the inspiratory flow and $\left|\dot{V}_{\text {exp }}\right|$ is the absolute value of expiratory flow.

\section{Statistics}

All data are given as mean \pm SD. The statistical analyses of the data were conducted with 1- or 2-way analyses of variance.

\section{Results}

\section{Generable Flow}

The inspiratory flow to the lungs was lower than the supply flow (Table 2). By contrast, the expiratory flow 
exceeded the supply flow in all measurements, except at a supply flow of $300 \mathrm{~mL} / \mathrm{s}$ and in tubes with an ID $<4.0 \mathrm{~mm}$. As a result, expiratory flow was always larger when compared with the inspiratory flow.

The maximal inspiratory and expiratory flow via active expiration assistance increased significantly with increasing supply flow and decreased with decreasing ID of the connected endotracheal tube (both $P<.001$, Table 2). Compared with an ETT with $8.0 \mathrm{~mm}$ ID, the inspiratory flow was reduced by $18.5 \%$, and the expiratory flow was reduced by $32.9 \%$ when the smallest tested endotracheal
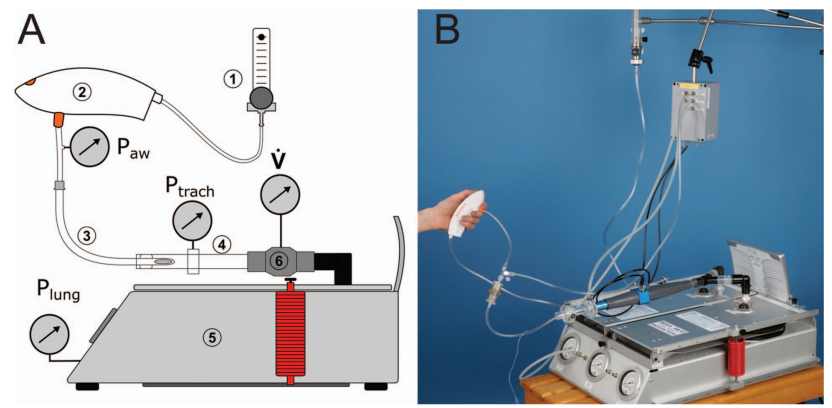

Fig. 2. Schematic (A) and photograph (B) of setups. A supply device (1) delivered the driving flow to the active expiration assistance device (2), which was connected via the respective tracheal tube (3) or catheter to a tracheal model (4). The tracheal model was connected to the physical lung model (5) via a pneumotachograph (6) for measuring flow $(\dot{V})$. Airway $\left(P_{\text {aw }}\right)$, tracheal $\left(P_{\text {trach }}\right)$, and lung $\left(P_{\text {lung }}\right)$ pressures were measured at the proximal and distal tips of the tracheal tube or catheter and inside the lung model, respectively. In the measurements including conventional ventilation, the active expiration assistance system was replaced by the ventilator. tube with $3.0 \mathrm{~mm}$ ID was used. Expiratory peak flow during volume controlled ventilation decreased with decreasing ID of the ETT (Table 3). With the cricothyrotomy catheter, inspiratory and expiratory flow were reduced by 16.5 and $34.4 \%$, respectively.

\section{Generable Minute Volumes}

Conventional ventilation could not be established using the cricothyrotomy catheter or using the ETT of $3.0 \mathrm{~mm}$ ID with inspiratory-expiratory ratio $1: 1.5$ and frequency of 15 breaths/min because the maximally selectable pressure limit of the ventilator's alarming system $\left(=100 \mathrm{~cm} \mathrm{H}_{2} \mathrm{O}\right)$ was continuously exceeded, and the ventilator aborted inspiration.

The minute volumes generated with active expiration assistance depended on the supply flow and on the IDs of the tracheal tube that was used. The higher the supply flow and the larger the ID of the tracheal tube, the more respiratory minute volume could be generated (see Table 2). Also, the minute volumes generated with conventional ventilation without causing a noticeable PEEPi $\left(<1 \mathrm{~cm} \mathrm{H}_{2} \mathrm{O}\right)$ depended on the supply flow and on the IDs of the tracheal tube used (Table 4). The PEEPi increased with smaller tracheal tube IDs and higher inspiratory-expiratory ratios. With ETTs of 8.0 and $7.0 \mathrm{~mm}$ ID, noticeable PEEPi did not occur in any of the tested ventilation situations. With a microlaryngeal tube of 4.0 and ETT of $3.0 \mathrm{~mm}$ ID, noticeable PEEPi occurred in each of the tested ventilation situations. Microlaryngeal tubes were more likely to generate a relevant PEEPi when compared with ETTs of same ID. During conventional ventilation, end-expiratory

Table 2. Generable Respiratory Flows and Minute Volumes of the Active Expiration Assistance as a Function of Supply Flow Rate With Different Tracheal Tubes or Catheter

\begin{tabular}{|c|c|c|c|c|c|c|c|c|}
\hline & \multicolumn{4}{|c|}{ Supply Flow 200 mL/s } & \multicolumn{4}{|c|}{ Supply Flow $300 \mathrm{~mL} / \mathrm{s}$} \\
\hline & Flow $_{\text {insp }}(\mathrm{mL} / \mathrm{s})$ & Flow $_{\exp }(\mathrm{mL} / \mathrm{s})$ & $\dot{\mathrm{V}}_{\mathrm{E} \text { meas }}(\mathrm{L} / \mathrm{min})$ & $\dot{\mathrm{V}}_{\mathrm{E} \text { calc }}(\mathrm{L} / \mathrm{min})$ & Flow $_{\text {insp }}(\mathrm{mL} / \mathrm{s})$ & Flow $_{\exp }(\mathrm{mL} / \mathrm{s})$ & $\dot{\mathrm{V}}_{\mathrm{E} \text { meas }}(\mathrm{L} / \mathrm{min})$ & $\dot{\mathrm{V}}_{\mathrm{E} \text { calc }}(\mathrm{L} / \mathrm{min})$ \\
\hline ETT 8.0 & $163.3 \pm 3.0$ & $-295.3 \pm 5.8$ & $6.3 \pm 0.1$ & 6.9 & $263.8 \pm 3.5$ & $-349.2 \pm 4.4$ & $9.0 \pm 0.1$ & 9.2 \\
\hline ETT 7.0 & $158.4 \pm 4.3$ & $-292.8 \pm 1.6$ & $6.2 \pm 0.1$ & 6.8 & $259.8 \pm 4.3$ & $-346.0 \pm 2.7$ & $8.9 \pm 0.1$ & 9.1 \\
\hline ETT 6.0 & $153.3 \pm 3.1$ & $-292.1 \pm 1.4$ & $6.1 \pm 0.1$ & 6.7 & $256.8 \pm 6.7$ & $-342.9 \pm 4.7$ & $8.8 \pm 0.1$ & 9.0 \\
\hline MLT 6.0 & $153.2 \pm 1.5$ & $-291.4 \pm 1.5$ & $6.1 \pm 0.1$ & 6.7 & $256.6 \pm 8.6$ & $-341.3 \pm 2.8$ & $8.8 \pm 0.1$ & 8.9 \\
\hline ETT 5.0 & $154.1 \pm 10.7$ & $-280.9 \pm 3.2$ & $6.0 \pm 0.2$ & 6.5 & $259.3 \pm 1.6$ & $-336.0 \pm 5.4$ & $8.8 \pm 0.1$ & 8.9 \\
\hline MLT 5.0 & $149.9 \pm 2.6$ & $-281.8 \pm 1.3$ & $5.9 \pm 0.1$ & 6.5 & $252.1 \pm 2.0$ & $-333.3 \pm 2.8$ & $8.6 \pm 0.1$ & 8.8 \\
\hline ETT 4.0 & $149.5 \pm 8.9$ & $-265.4 \pm 4.3$ & $5.8 \pm 0.2$ & 6.2 & $229.7 \pm 14.0$ & $-329.5 \pm 16.5$ & $8.1 \pm 0.2$ & 8.4 \\
\hline MLT 4.0 & $144.0 \pm 1.7$ & $-247.4 \pm 1.6$ & $5.5 \pm 0.1$ & 5.9 & $240.8 \pm 9.4$ & $-298.3 \pm 6.1$ & $8.0 \pm 0.2$ & 8.1 \\
\hline ETT 3.0 & $133.2 \pm 4.4$ & $-219.2 \pm 1.4$ & $5.0 \pm 0.1$ & 5.3 & $227.2 \pm 13.2$ & $-265.9 \pm 8.5$ & $7.3 \pm 0.3$ & 7.3 \\
\hline Cricath & $136.3 \pm 5.9$ & $-193.7 \pm 7.7$ & $4.8 \pm 0.1$ & 5.0 & $208.3 \pm 19.0$ & $-246.5 \pm 17.0$ & $6.7 \pm 0.2$ & 6.8 \\
\hline \multicolumn{9}{|c|}{$\begin{array}{l}\text { ETT }=\text { endotracheal tube } \\
\text { MLT = microlaryngeal tube } \\
\dot{V}_{\text {E meas }}=\text { measured respiratory minute volume } \\
\dot{\mathrm{V}}_{\text {E calc }}=\text { calculated respiratory minute volume } \\
\text { Flow }_{\text {insp }}=\text { inspiratory flow } \\
\text { Flow }_{\text {exp }} \text { = expiratory flow }\end{array}$} \\
\hline
\end{tabular}




\section{Active Expiration Assistance}

Table 3. Expiratory Peak Flow During Conventional Ventilation Depending on Frequency and Different Tracheal Tubes or Catheter

\begin{tabular}{|c|c|c|c|c|c|c|c|c|}
\hline & \multicolumn{8}{|c|}{ Expiratory Peak Flow (L/min) } \\
\hline & \multicolumn{4}{|c|}{ I:E $1: 1.5$} & \multicolumn{4}{|c|}{ I:E $1: 1$} \\
\hline & $\begin{array}{c}\text { Frequency } 6 \\
\text { breaths/min }\end{array}$ & $\begin{array}{c}\text { Frequency } 9 \\
\text { breaths/min }\end{array}$ & $\begin{array}{c}\text { Frequency } 12 \\
\text { breaths/min }\end{array}$ & $\begin{array}{c}\text { Frequency } 15 \\
\text { breaths/min }\end{array}$ & $\begin{array}{c}\text { Frequency } 6 \\
\text { breaths/min }\end{array}$ & $\begin{array}{c}\text { Frequency } 9 \\
\text { breaths/min }\end{array}$ & $\begin{array}{c}\text { Frequency } 12 \\
\text { breaths/min }\end{array}$ & $\begin{array}{c}\text { Frequency } 15 \\
\text { breaths/min }\end{array}$ \\
\hline ETT 8.0 & $-578 \pm 4$ & $-580 \pm 9$ & $-585 \pm 8$ & $-594 \pm 7$ & $-582 \pm 8$ & $-583 \pm 7$ & $-590 \pm 7$ & $-607 \pm 7$ \\
\hline ETT 7.0 & $-508 \pm 8$ & $-512 \pm 7$ & $-518 \pm 9$ & $-528 \pm 8$ & $-510 \pm 8$ & $-514 \pm 7$ & $-525 \pm 7$ & $-550 \pm 6$ \\
\hline ETT 6.0 & $-421 \pm 22$ & $-426 \pm 23$ & $-436 \pm 23$ & $-455 \pm 21$ & $-423 \pm 24$ & $-430 \pm 23$ & $-450 \pm 21$ & $-483 \pm 15$ \\
\hline MLT 6.0 & $-407 \pm 16$ & $-415 \pm 18$ & $-427 \pm 18$ & $-449 \pm 15$ & $-413 \pm 20$ & $-420 \pm 19$ & $-444 \pm 15$ & $-481 \pm 12$ \\
\hline ETT 5.0 & $-336 \pm 17$ & $-345 \pm 19$ & $-364 \pm 18$ & $-394 \pm 13$ & $-338 \pm 17$ & $-354 \pm 18$ & $-388 \pm 13$ & $-430 \pm 10$ \\
\hline MLT 5.0 & $-323 \pm 13$ & $-334 \pm 14$ & $-356 \pm 13$ & $-388 \pm 10$ & $-327 \pm 14$ & $-345 \pm 13$ & $-381 \pm 9$ & $-424 \pm 8$ \\
\hline ETT 4.0 & $-228 \pm 11$ & $-251 \pm 8$ & $-287 \pm 6$ & $-329 \pm 7$ & $-234 \pm 11$ & $-269 \pm 7$ & $-319 \pm 5$ & $-373 \pm 6$ \\
\hline MLT 4.0 & $-210 \pm 2$ & $-239 \pm 2$ & $-276 \pm 2$ & $-320 \pm 2$ & $-219 \pm 2$ & $-259 \pm 2$ & $-310 \pm 3$ & $-366 \pm 3$ \\
\hline ETT 3.0 & $-158 \pm 5$ & $-198 \pm 6$ & $-245 \pm 3$ & $-341 \pm 2$ & $-174 \pm 5$ & $-226 \pm 2$ & $-278 \pm 2$ & NA \\
\hline Cricath & NA & NA & NA & NA & NA & NA & NA & NA \\
\hline \multicolumn{9}{|c|}{$\begin{array}{l}\mathrm{I}: \mathrm{E}=\text { ratio of inspiratory to expiratory time } \\
\text { ETT = endotracheal tube } \\
\text { MLT = microlaryngeal tube } \\
\text { NA = not available }\end{array}$} \\
\hline
\end{tabular}

Table 4. Intrinsic PEEP During Volume Controlled Ventilation on Lung Model (Tidal Volume $=640 \mathrm{~mL}$ ) Depending on Frequency, InspiratoryExpiratory Time, and Endotracheal Tube or Catheter

\begin{tabular}{|c|c|c|c|c|c|c|c|c|}
\hline & \multicolumn{8}{|c|}{ PEEPi $\left(\mathrm{cm} \mathrm{H}_{2} \mathrm{O}\right)$} \\
\hline & \multicolumn{2}{|c|}{ Frequency 6 breaths/min } & \multicolumn{2}{|c|}{ Frequency 9 breaths/min } & \multicolumn{2}{|c|}{ Frequency 12 breaths/min } & \multicolumn{2}{|c|}{ Frequency 15 breaths/min } \\
\hline & I:E 1:1.5 & I:E $1: 1$ & I:E 1:1.5 & I:E $1: 1$ & I:E $1: 1.5$ & I:E $1: 1$ & I:E 1:1.5 & I:E 1:1 \\
\hline ETT 8.0 & $0.0 \pm 0.0$ & $0.1 \pm 0.1$ & $0.0 \pm 0.0$ & $0.1 \pm 0.0$ & $0.1 \pm 0.0$ & $0.2 \pm 0.0$ & $0.2 \pm 0.0$ & $0.5 \pm 0.0$ \\
\hline ETT 7.0 & $0.0 \pm 0.0$ & $0.0 \pm 0.1$ & $0.1 \pm 0.1$ & $0.1 \pm 0.1$ & $0.2 \pm 0.1$ & $0.4 \pm 0.1$ & $0.4 \pm 0.1$ & $0.9 \pm 0.1$ \\
\hline ETT 6.0 & $0.0 \pm 0.0$ & $0.1 \pm 0.1$ & $0.2 \pm 0.1$ & $0.3 \pm 0.1$ & $0.4 \pm 0.1$ & $0.8 \pm 0.1$ & $0.9 \pm 0.1$ & $1.7 \pm 0.1$ \\
\hline MLT 6.0 & $0.0 \pm 0.0$ & $0.2 \pm 0.1$ & $0.2 \pm 0.1$ & $0.4 \pm 0.1$ & $0.5 \pm 0.1$ & $1.0 \pm 0.0$ & $1.1 \pm 0.0$ & $2.0 \pm 0.0$ \\
\hline ETT 5.0 & $0.1 \pm 0.1$ & $0.2 \pm 0.1$ & $0.4 \pm 0.1$ & $0.8 \pm 0.0$ & $1.1 \pm 0.0$ & $2.0 \pm 0.1$ & $2.2 \pm 0.1$ & $3.7 \pm 0.1$ \\
\hline MLT 5.0 & $0.1 \pm 0.1$ & $0.3 \pm 0.1$ & $0.5 \pm 0.1$ & $1.0 \pm 0.0$ & $1.4 \pm 0.0$ & $2.4 \pm 0.0$ & $2.6 \pm 0.0$ & $4.2 \pm 0.0$ \\
\hline ETT 4.0 & $0.6 \pm 0.1$ & $1.0 \pm 0.1$ & $2.1 \pm 0.1$ & $3.2 \pm 0.0$ & $4.3 \pm 0.0$ & $6.7 \pm 0.1$ & $7.3 \pm 0.0$ & $11.0 \pm 0.0$ \\
\hline MLT 4.0 & $1.2 \pm 0.1$ & $1.9 \pm 0.0$ & $3.3 \pm 0.1$ & $5.0 \pm 0.1$ & $6.4 \pm 0.2$ & $9.6 \pm 0.2$ & $10.4 \pm 0.2$ & $15.1 \pm 0.1$ \\
\hline ETT 3.0 & $3.8 \pm 0.2$ & $5.9 \pm 0.2$ & $9.4 \pm 0.2$ & $13.3 \pm 0.3$ & $17.0 \pm 0.1$ & $22.8 \pm 0.3$ & NA & $36.6 \pm 0.7$ \\
\hline Cricath & NA & NA & NA & NA & NA & NA & NA & NA \\
\hline $\begin{array}{l}\text { Boldface valu } \\
\text { PEEPi = intri } \\
\text { I:E = inspirat } \\
\text { ETT = endotr } \\
\text { MLT = micro } \\
\text { NA = not ava } \\
\text { cricothyrotom }\end{array}$ & $\begin{array}{l}\text { licate noticeable } \\
\text { EEP } \\
\text { expiration ratio } \\
\text { l tube } \\
\text { geal tube } \\
\text { Ventilation co } \\
\text { heter because th }\end{array}$ & sic PEEP values & $\begin{array}{l}\text { ETT of } 3.0 \mathrm{r} \\
\mathrm{r} \text { were contin }\end{array}$ & $\begin{array}{l}\text { ith a ratio of } \\
\text { xceeded. }\end{array}$ & to expiratory & $: 1.5$ and freq & 15 breaths $/ \mathrm{m}$ & \\
\hline
\end{tabular}

pressure in the lung increased with increasing PEEPi from $5.0 \pm 0.1 \mathrm{~cm} \mathrm{H}_{2} \mathrm{O}$ (ETT $8.0 \mathrm{~mm} \mathrm{ID)}$ to $41.6 \pm 0.8 \mathrm{~cm} \mathrm{H}_{2} \mathrm{O}$ (Cricath), and end-inspiratory pressure in the lung increased with increasing PEEP from $13.7 \pm 0.1 \mathrm{~cm} \mathrm{H}_{2} \mathrm{O}$ (ETT $8.0 \mathrm{~mm}$ ID) to $49.7 \pm 0.9 \mathrm{~cm} \mathrm{H}_{2} \mathrm{O}$ (Cricath). With active expiration assistance, end-expiratory $\left(4.2 \pm 0.1 \mathrm{~cm} \mathrm{H}_{2} \mathrm{O}\right)$ and end-inspiratory pressures $\left(12.9 \pm 0.2 \mathrm{~cm} \mathrm{H}_{2} \mathrm{O}\right)$ in the lung could be kept constant throughout all conditions.
Conventional ventilation allowed larger minute volumes than ventilation with active expiration assistance when ETTs of 7 or $8 \mathrm{~mm}$ ID were used (Fig. 3). With small tracheal tubes, active expiration assistance generated similar or higher minute volumes compared with conventional ventilation. When using active expiration assistance, the altered flow led to a change of the I-E ratio (see Table 2). 


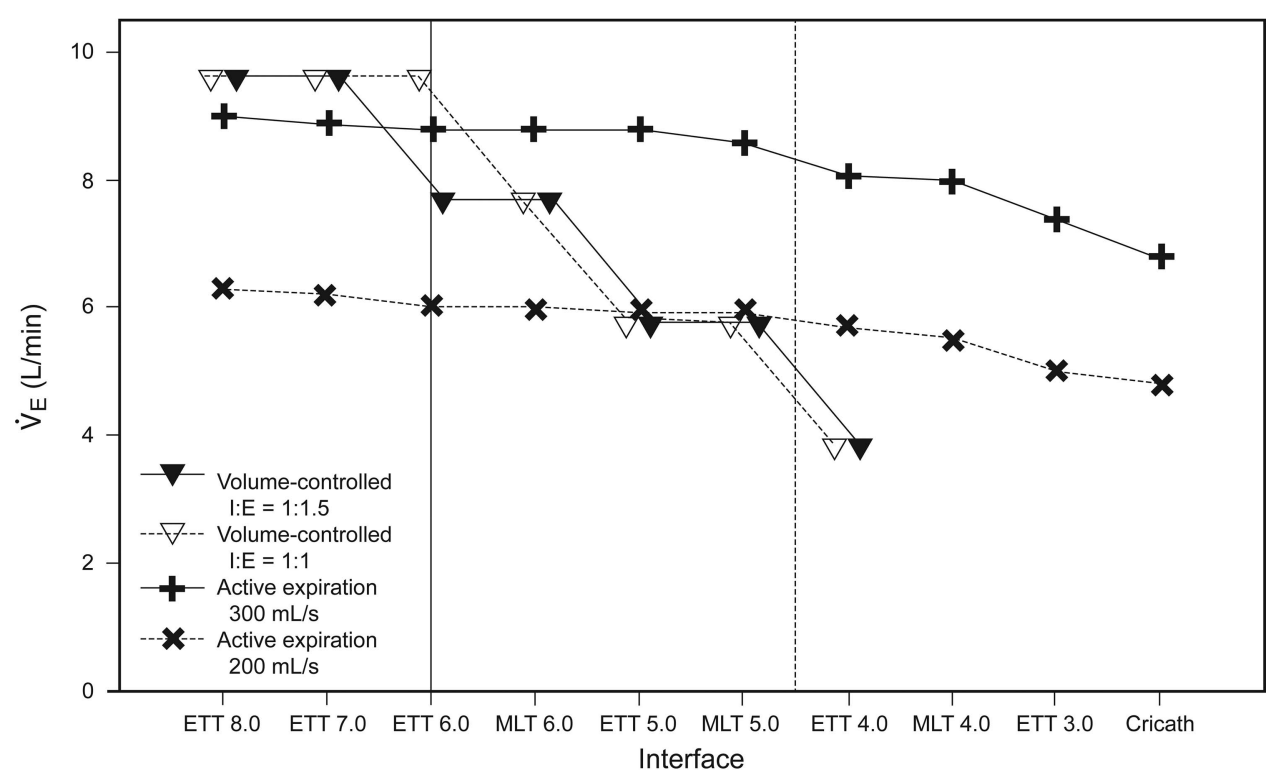

Fig. 3. Comparison of the respiratory minute volumes achieved via active expiration assistance and via volume-controlled ventilation (tidal volume $=640 \mathrm{~mL}$, PEEP $=5 \mathrm{~cm} \mathrm{H}_{2} \mathrm{O}$ ) without generating intrinsic PEEP $\left(\geq 1 \mathrm{~cm} \mathrm{H}_{2} \mathrm{O}\right)$. Vertical lines represent the cut-off where ventilation via active expiration assistance with $200 \mathrm{~mL} / \mathrm{s}$ (solid) or $300 \mathrm{~mL} / \mathrm{s}$ (dashed) was superior to conventional mechanical ventilation (viewed from right to left) in terms of higher generable minute volume (as indicated by the crossings of the connecting lines). Missing values (volumecontrolled ventilation for MLT 4.0, ETT 3.0 and cricath) indicate that no conventional ventilation could be established without generating intrinsic PEEP $<1 \mathrm{~cm} \mathrm{H}_{2} \mathrm{O}$. ETT = endotracheal tube; $\mathrm{MLT}=$ microlaryngeal tube; cricath = cricothyrotomy catheter.

\section{Discussion}

The main results of the present study can be summarized as follows: (1) active expiration assistance can generate minute volumes within the clinically relevant range, and (2) the minute volumes generated with active expiration assistance depend on the tracheal tube's ID but less than the minute volumes generated with conventional ventilation without causing PEEPi. The hypothesis of the present study was that PEEPi can be avoided by applying an active expiration support system, and our findings confirm this for small tracheal tubes and cricothyrotomy catheters.

During perioperative mechanical ventilation, the tracheal tube is usually the connection between the artificial and the native airways. It represents the narrowest part of the respiratory system. Microlaryngeal tubes are often used in vocal cord surgery to optimize the surgical field. Due to the particularly small cross-sectional area in microlaryngeal tubes, their resistance is considerably larger when compared with ETTs otherwise used in adult patients. As a consequence, the risk of incomplete expiration and resulting PEEPi is increased when microlaryngeal tubes are used. ${ }^{2}$

With both conventional ventilation and active expiration assistance, the generated minute volumes depended on the tracheal tubes size. The active expiration assistance was not advantageous with tracheal tubes of large ID $(>7.0 \mathrm{~mm})$ (ie, small resistance). However, whereas ac- tive expiration assistance generated a reasonable minute ventilation even with the smallest tracheal tubes that were tested in this study and with the cricothyrotomy catheter, conventional mechanical ventilation with passive expiration was associated with intolerable levels of PEEPi in certain situations, particularly in ETTs with small ID or microlaryngeal tubes, and was not applicable with the cricothyrotomy catheter. With conventional ventilation, a noticeable PEEPi was generated more likely when ETTs with low ID or particularly microlaryngeal tubes were used, compared with normally sized ETTs. As a consequence, the active expiration assistance was superior in generating minute volume to conventional ventilation when used with ETTs with low ID or with microlaryngeal tubes. Consequently, the minute volume of the active expiration assistance depended less on the ETT than that seen with the use of conventional ventilation. The majority of adult patients who undergo ETT intubation receive an ETT with an ID of $\geq 6.5 \mathrm{~mm}$. However, in certain cases, the use of smalllumen tracheal tubes is preferable (eg, in ear-nose-throat surgery, where microlaryngeal tubes are used to allow a better field of view for the surgeon). From another point of view, the active expiration assistance would allow the choice of a tracheal tube independent of its diameter without increasing the potential risk of PEEPi.

During conventional ventilation, the elasticity of the respiratory system generates the driving force for passive expiration. The time for complete passive expiration is 
determined by 2 variables of the respiratory system, compliance and resistance. The lower the elastic forces and the higher the resistive forces, the more time that is needed to fully exhale the tidal volume. If the expiration is interrupted by the following inspiration, the lung volume is higher than the physiological functional residual capacity after full expiration. ${ }^{5}$ This situation is termed dynamic hyperinflation, resulting in alveolar end-expiratory pressure being higher than the desired (extrinsic) PEEP as set on the ventilator. The difference between alveolar endexpiratory pressure and extrinsic PEEP is the PEEPi.7,8

The incidence of PEEPi is reported in the literature to be up to $47 \% .{ }^{9}$ Factors for increased risk of intrinsic PEEP are flow limitation, ventilation settings, and resistance of the respiratory system. ${ }^{3}$ The tracheal tube as the narrowest part of the respiratory system determines predominantly the resistance of the artificial airways. ${ }^{4}$ In studies in physical models, the influence of the tracheal tube's ID on the risk of PEEPi and the benefit of compensating for the tube's resistance were well documented, ${ }^{2}$ and the use of large bore tubes was recommended to prevent PEEPi. ${ }^{5}$

The possible negative effects of PEEPi and its corresponding clinical correlate, dynamic hyperinflation, have frequently been described in the literature: PEEPi leads to an increase in the resistive and elastic work of breathing. ${ }^{10}$ Furthermore, PEEPi can negatively influence gas exchange. Brandolese et $\mathrm{al}^{11}$ studied the effects of PEEPi on gas exchange and determined that in subjects with PEEPi, $\mathrm{P}_{\mathrm{aO}_{2}}$ was lower than in those without. The authors attributed this to a less homogeneous gas distribution in the lungs at PEEPi compared with the situation at actively applied PEEP. In addition, PEEPi may have a negative hemodynamic effect. ${ }^{6,11,12}$ In particular situations, PEEPi may also have lung-protective effects because it increases the total PEEP. ${ }^{13}$ However, PEEPi is not a controllable variable because it is not continuously accessible. Therefore, PEEPi should be avoided to protect the patient from potential harm.

Patients with flow limitation are at particular risk for PEEPi, and the application of a set expiratory flow may aggravate the associated dynamic hyperinflation. However, in contrast to passive expiration, controlling the expiratory flow would allow setting a flow below the limitation, which might potentially be beneficial for these patients.

Automatic tube compensation (ATC) could be considered as an approach in preventing PEEPi. ${ }^{14}$ ATC was developed to compensate for the resistance of the tracheal tube during spontaneous breathing, thereby facilitating complete expiration. Haberthür et $\mathrm{al}^{2}$ were able to avoid the occurrence of dynamic hyperinflation in a lung model using expiratory ATC during controlled ventilation. However, for safety reasons, commercially available ventilators have not to date allowed for the application of subatmospheric pressure during expiration but rather decrease the pressure at the ventilator's site below PEEP unless the pressure in the trachea approximates this level. A limitation is that ATC generates large expiratory peak flow, which is contraindicated in patients with flow limitation. Patients with COPD and asthma are predisposed to collapse of the small airways during expiration when high expiratory flow is present. In these patients, expiratory support in terms of accelerated flow would be contraindicated because it may result in dynamic hyperinflation. ${ }^{15}$ It is important to state that the active expiration achieved with the active expiration assistance is not associated with an accelerated expiration. Despite active expiration, the expiratory flow generated via the Bernoulli principle is nearly constant and clearly lower than peak flows that are typically observed in clinical practice. With active expiration assistance, a continuous expiratory flow is generated for the whole expiration time, and as a consequence, expiration occurs in a controlled fashion (comparable with the pursed lip expiration technique that is seen in patients with chronic obstructive pulmonary diseases) rather than being merely accelerated.

Also in this context, it has to be noted that active expiration generates a negative airway pressure during expiration but does not necessarily generate negative pressure at the distal end of the tracheal tube (ie, in the trachea). The negative pressure generates a controlled gas outflow from the lungs that is lower than expiratory peak flow during conventional expiration if conventional ETTs are used. This means that the pressure in the lungs remains positive unless the tidal volume is extracted. Consequently, a ventilator system utilizing the presented approach should be capable of monitoring the pressure proximal to the tip of the tube, either by calculating or by measuring tracheal pressure. For the first approach, the resistance coefficients of the respective endotracheal tubes ${ }^{4}$ could be used; the latter could be achieved via a side port lumen of the tracheal tube. If, during ongoing expiration, the measured or calculated tracheal pressure approximates the desired PEEP level, active expiration would then be ended, and the proceeding inspiration would be initiated. Such ventilation principle would rule out the development of PEEPi.

\section{Limitations of the Study}

The major limitation of our study is that it is a bench study, and the results will need to be validated in a clinical setting. We chose the approach via the lung model for the following reasons: Measurements of intratracheal pressure and particularly measurements of flow and continuous determination of PEEPi would not be possible in patients. Furthermore, we have investigated situations of extreme PEEPi and minute volume, and the various tracheal tubes could be used in the same model, resulting in reproducible 
circumstances. It would not have been possible to investigate these conditions in patients.

In further studies, the potential benefits of active expiration assistance need to be tested in patients. In such studies, any potential risk for atelectatic trauma by negative pressure in the patient's respiratory system must be prevented. A ventilator based on the principle of active expiration assistance would therefore require calculation or direct measurement of tracheal pressure to exclude the development of tracheal pressure below PEEP. However, by such an approach, PEEPi would be ruled out per se, since the end of expiration would be determined by reaching PEEP in the trachea.

The ventilation settings in this study simulated circumstances with increased risk for development of PEEPi. We have chosen a comparably high patient compliance and included tubes with comparably high resistance (ie, smalllumen tubes). Because most patients can be sufficiently ventilated with conventional ventilation, our results might be relevant in particular situations (ie, when small-lumen tubes [eg, microlaryngeal tubes] are used and/or if patients show large compliance).

\section{Conclusions}

PEEPi may occur during mechanical ventilation with endotracheal tubes of low ID. Particularly, ventilation with specific endotracheal tubes with particularly small cross sections increases the risk of PEEPi. When using endotracheal tubes with a small ID, microlaryngeal tubes, or cricothyrotomy catheters, a reasonable respiratory minute volume can be achieved through active expiration without generating PEEPi. The minute volumes generated via active expiration assistance are less dependent on the tracheal tube used than those of conventional ventilation with passive expiration. If small-lumen tubes are required in clinical situations, active expiration might be a necessary means for active compensation of flow resistance to generate adequate minute ventilation without causing PEEPi.

\section{ACKNOWLEDGMENT}

We thank Con Lehane for language editing.

\section{REFERENCES}

1. Haberthür C, Elsasser S, Eberhard L, Stocker R, Guttmann J. Total versus tube-related additional work of breathing in ventilator-dependent patients. Acta Anaesthesiol Scand 2000;44(6):749-757.

2. Haberthür C, Mehlig A, Stover JF, Schumann S, Möller K, Priebe HJ, Guttmann J. Expiratory automatic endotracheal tube compensation reduces dynamic hyperinflation in a physical lung model. Crit Care 2009;13(1):R4.

3. Natalini G, Tuzzo D, Rosano A, Testa M, Grazioli M, Pennestri V, et al. Assessment of factors related to auto-PEEP. Respir Care 2016; 61(2):134-141.

4. Wright PE, Marini JJ, Bernard GR. In vitro versus in vivo comparison of endotracheal tube airflow resistance. Am Rev Respir Dis 1989;140(1):10-16.

5. Rossi A, Polese G, Brandi G, Conti G. Intrinsic positive end-expiratory pressure (PEEPi). Intensive Care Med 1995;21(6):522-536.

6. Berry M, Tzeng Y, Marsland C. Percutaneous transtracheal ventilation in an obstructed airway model in post-apnoeic sheep. Br J Anaesth 2014;113(6):1039-1045.

7. Brochard L. Intrinsic (or auto-) PEEP during controlled mechanical ventilation. Intensive Care Med 2002;28(10):1376-1378.

8. Rossi A, Gottfried SB, Zocchi L, Higgs BD, Lennox S, Calverley $\mathrm{PM}$, et al. Measurement of static compliance of the total respiratory system in patients with acute respiratory failure during mechanical ventilation: the effect of intrinsic positive end-expiratory pressure. Am Rev Respir Dis 1985;131(5):672-677.

9. Wright J, Gong H Jr. "Auto-PEEP”: incidence, magnitude, and contributing factors. Heart Lung 1990;19(4):352-357.

10. MacIntyre NR, Cheng KC, McConnell R. Applied PEEP during pressure support reduces the inspiratory threshold load of intrinsic PEEP. Chest 1997;111(1):188-193.

11. Brandolese R, Broseghini C, Polese G, Bernasconi M, Brandi G, Milic-Emili J, Rossi A. Effects of intrinsic PEEP on pulmonary gas exchange in mechanically-ventilated patients. Eur Respir J 1993; 6(3):358-363.

12. Rossi A, Santos C, Roca J, Torres A, Félez MA, Rodriguez-Roisin R. Effects of PEEP on VA/Q mismatching in ventilated patients with chronic airflow obstruction. Am J Respir Crit Care Med 1994;149(5): 1077-1084.

13. de Durante G, del Turco M, Rustichini L, Cosimini P, Giunta F, Hudson LD, et al. ARDSNet lower tidal volume ventilatory strategy may generate intrinsic positive end-expiratory pressure in patients with acute respiratory distress syndrome. Am J Respir Crit Care Med 2002;165(9):1271-1274.

14. Guttmann J, Haberthür C, Mols G, Lichtwarck-Aschoff M. Automatic tube compensation (ATC). Minerva Anestesiol 2002;68(5): 369-377.

15. Ward NS, Dushay KM. Clinical concise review: mechanical ventilation of patients with chronic obstructive pulmonary disease. Crit Care Med 2008;36(5):1614-1619.

This article is approved for Continuing Respiratory Care Education credit. For information and to obtain your CRCE

(free to AARC members) visit www.rcjournal.com

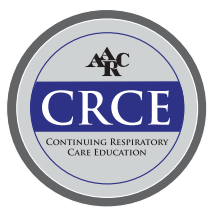

